\title{
Injury To Jugular Vein, CTCAE
}

National Cancer Institute

\section{Source}

National Cancer Institute. Injury To Jugular Vein, CT CAE. NCI Thesaurus. Code C143587.

A finding of damage to the jugular vein. 